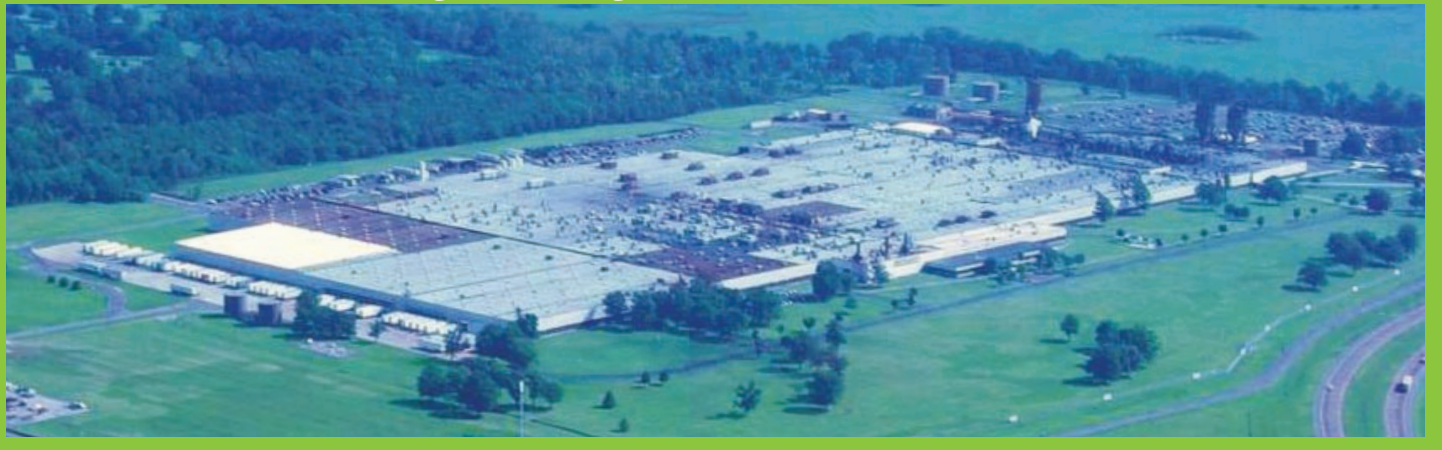

Goodyear operates more than 60 facilities in 26 countries, including the Union City, Tennessee, plant pictured above.

\title{
Goodyear Tire Plant Gains Traction on Energy Savings After Completing Save Energy Now Assessment
}

\section{Saves \$875,000 in Energy Costs; Reduces Natural Gas Consumption}

\section{Benefits}

- Implemented approximately $\$ 875,000$ in annual energy cost savings

- Achieves annual natural gas savings of more than 93,000 MMBtu

- Reduces No. 6 fuel oil consumption by more than 224,000 gallons per year

- Yields a simple payback of 2.5 months

\section{Key Findings}

- Even if a company is already actively managing its energy use, an independent evaluation can bolster energy savings efforts —oftentimes with a minor investment and significant payback in a short amount of time.

-While Goodyear's energy management program was effective, the Save Energy Now assessment substantiated the energy savings potential of larger-scale projects.

- By optimizing boiler operation and improving insulation, Goodyear significantly reduced fossil fuel consumption.

- The success of the assessment has prompted Goodyear to share the energy savings recommendations with its other facilities.

\section{Applications}

Steam systems are often found in large tire plants and can account for a significant part of a plant's energy consumption. Detailed analyses of steam system performance and energy use in such plants can uncover opportunities to improve system efficiency, which can generate significant energy savings.

\section{Summary}

In March 2006, a U.S. Department of Energy (DOE) Save Energy Now assessment was conducted for Goodyear at the company's tire plant in Union City, Tennessee. Plant associates had long suspected that their steam system could yield significant energy savings. Working with DOE Energy Expert Don Schmidt of Geos LLC, plant personnel learned how to analyze and identify natural gas savings opportunities in the plant's steam system utilizing DOE's suite of steam system assessment software tools.

While the assessment identified three main recommendations, Goodyear chose to first implement the opportunity that would yield the greatest energy savings. They improved their boiler operation and load management strategy, and then began insulating their process equipment. Once the insulation project is completed, the company will have reduced its natural gas use by 93,000 MMBtu and No. 6 fuel oil consumption by 224,000 gallons - for a total annual savings of more than 127,000 MMBtu and nearly $\$ 875,000$ in energy cost savings. With implementation costs of $\$ 180,000$, the plant will achieve a simple payback of 2.5 months. In addition, Goodyear personnel indicated that some of the recommendations were applicable to a number of their other tire plants.

\section{U.S. Department of Energy}




\section{Project Drivers}

The Goodyear plant has a longstanding energy management policy that is aggressively focused on keeping steam traps in good working order and repairing leaks on a continuous basis. Faced with rising energy costs and the need to remain competitive, plant employees had contemplated additional efficiency improvements to their steam and motor-driven systems. The DOE Save Energy Now assessment report added weight to concerns that had been raised by the plant energy team. After evaluating the implementation costs and resources needed to apply the recommendations, plant management determined that the effort was viable and fully supported it.

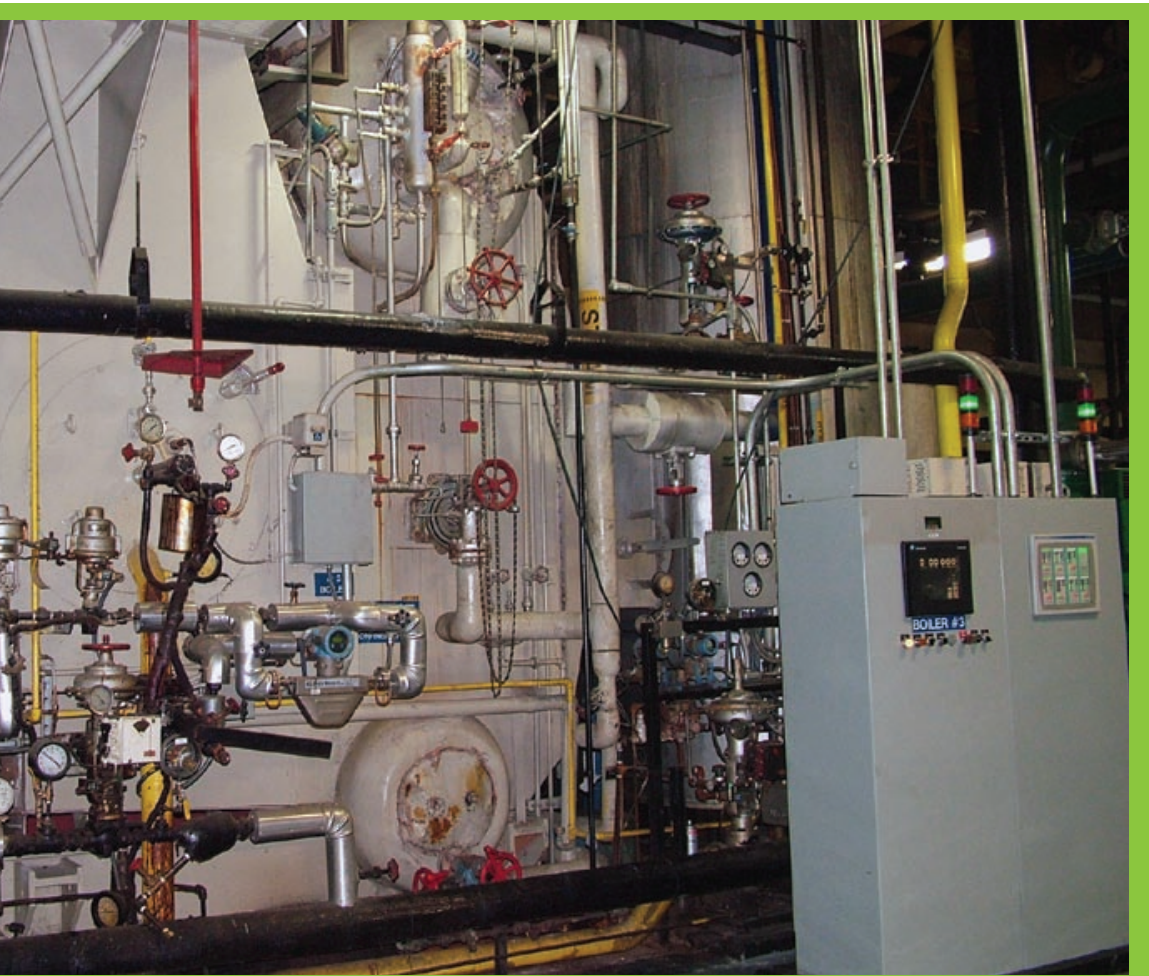

The steam system at Goodyear's Union City plant is served by four dual fueled (natural gas and No. 6 fuel oil) boilers, such as the $60,000 \mathrm{lbs} / \mathrm{hr}$ boiler pictured above.
Founded in 1898, Goodyear is one of the world's largest tire companies, with 70,000 employees and more than 60 tire plants in 26 countries. Goodyear develops, markets, and sells more than 80 different types of tires for a wide variety of vehicles. In 2006, the company posted net sales of $\$ 20.3$ billion. The Union City, Tennessee, plant opened its doors in 1968 and employs approximately 2,800 workers.

The steam system at the Union City plant is served by four dual fueled (natural gas and No. 6 fuel oil) boilers. The plant uses more than 400,000 MMBtu of natural gas and 4 million gallons of No. 6 fuel oil annually. Steam is important for the Union City plant's production because it is needed for critical applications such as tire curing and processing. Because many of the steam traps are located next to each of the plant's presses, steam trap maintenance is critical to ensuring that the presses operate reliably. The plant has an aggressive energy management program that monitors and repairs steam system leaks and malfunctioning steam traps on a regular basis.

\section{Assessment Overview}

The Save Energy Now assessment at Goodyear's Union City plant was sponsored by DOE's Industrial Technologies Program (ITP). The assessment was performed by an Energy Expert who worked with two plant employees to analyze the plant's steam system. As a Qualified Specialist in the use of DOE's steam system assessment tool (SSAT) software, the Energy Expert installed the program on the employees' computers and reviewed the data with them. This not only helped the plant team learn the software, but it also showed them how to continue to improve the steam system's efficiency and apply those practices to other Goodyear facilities. 


\section{Assessment Recommendations}

Using the data collected in the SSAT software, the team identified three potential energy savings measures and evaluated each for technical and economic feasibility. After reviewing expected cost and energy savings and the associated payback periods, the team determined the following near- and medium- term opportunities.

\section{Near-term opportunity}

\section{- Optimize Boiler Operation and Load Man- agement Strategy-The steam load profile showed that the plant operated all four boilers at part load for redundancy purposes. In addi- tion, two boilers were operating with excess flue gas oxygen levels and the air inlet temperatures were unnecessarily hot. Careful analysis of the plant's reliability requirements showed that the plant's steam demand could be met by operat- ing the large boiler and one of the small boilers at higher loads. To achieve this the plant would have to:}

- Tune all boilers to reduce excess oxygen (O2) levels

- Reconfigure the forced draft fan on the large boiler so that the fan inlet was closer to the ceiling of the boiler room

- Redirect the HVAC outlets away from the forced draft fan inlets on the smaller boilers. The assessment showed that these measures would increase boiler efficiency and save 70,000 MMBtu of natural gas and more than $\$ 500,000$ annually.

\section{Medium-term opportunities}

- Recover Process Waste Heat-Due to contaminants from the production process, a significant quantity of condensate is unsuitable for return to the boiler. This condensate is diverted to a "hot well" where it is cooled in a cooling tower, and then used to cool other plant processes. The assessment showed that the condensate's heat could be recovered using a heat exchanger to raise make-up water temperature, which would reduce the load on the boilers. Annual energy savings were estimated at 9,600 MMBtu of natural gas and 94,100 gallons of No. 6 oil. Estimated annual cost savings were approximately $\$ 176,000$ per year.

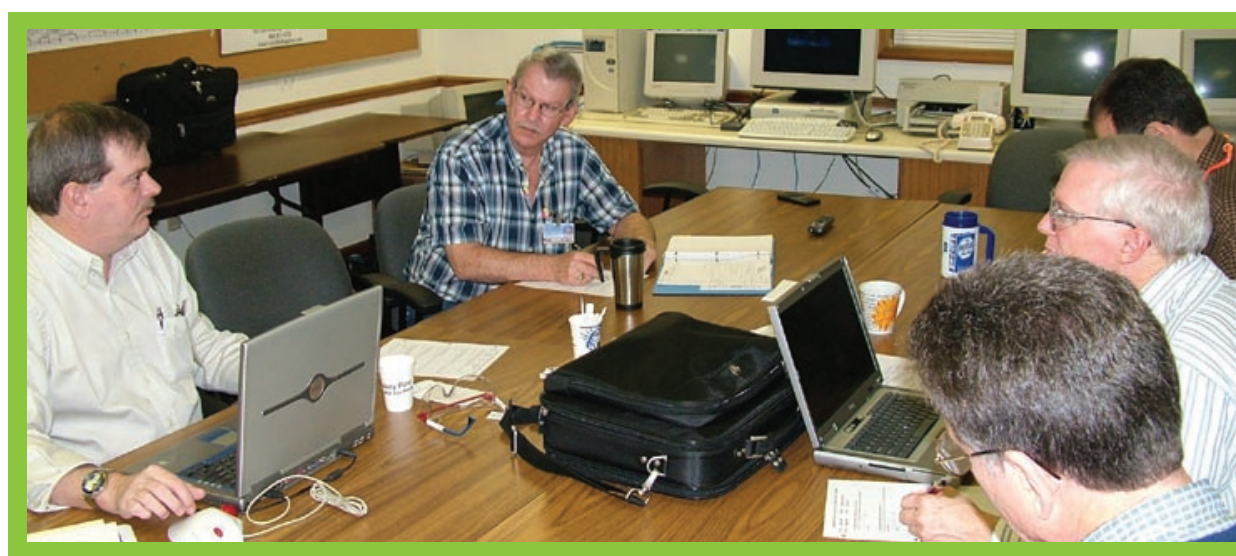

DOE Energy Expert Don Schmidt (far left), working with the Union City plant's energy team. Together they analyzed the plant's steam system using DOE's steam system assessment tool (SSAT) software, reviewed the results, and discussed next steps.

\section{"The Goodyear Union City plant had an energy conservation program active at the time of the audit, but the DOE audit helped to refocus our efforts and identify issues that would be better moved to the top of our task list."}

\section{-Dennis Burden, Mechanical Engineer, Goodyear}

- Insulate Process Equipment-While much of the steam system, including the headers, was insulated, the plant's tire presses were only partially insulated. The assessment calculated that the plant was losing approximately 1,500 $\mathrm{lbs} / \mathrm{hr}$ of steam. It was recommended that the plant completely insulate the presses to reduce steam demand, which would lower steam system energy consumption. Annual energy savings were estimated at almost 23,000 MMBtu of natural gas and more than 224,000 gallons of No. 6 oil, with total annual cost savings of around $\$ 400,000$.

If implemented, the total annual energy cost savings from both the near- and medium-term opportunities was estimated at more than $\$ 1$ million. 


\section{Results}

Goodyear's Union City plant personnel began optimizing boiler operation and working on a load management strategy shortly after the assessment was completed. In 2007, they started insulating the process equipment. To optimize boiler operation, the employees adjusted the automation controls on all the boilers and reconfigured the forced draft fan inlets as specified in the assessment. This enabled them to operate the large boiler closer to full load and shut down one of the smaller, natural gas fired boilers, resulting in annual energy and cost savings of approximately 70,000 MMBtu and $\$ 490,000$.

To insulate the tire presses, plant personnel purchased and installed heat blankets on each of the presses. This project was completed at the end of 2007, and is yielding annual energy savings of approximately 23,000 MMBtu of natural gas and 224,000 gallons of No. 6 fuel oil, and cost savings of $\$ 385,000$. The plant intends to implement the third opportunity, recovery of process waste heat, during a future scheduled plant shutdown.

Total energy savings from the implementation of the two recommendations is estimated at approximately 93,000 MMBtu of natural gas and 224,000 gallons of No. 6 fuel oil. With total implementation costs of $\$ 180,000$ and annual energy cost savings of $\$ 875,000$, these achievements will yield a simple payback of just 2.5 months. The plant's natural gas costs have declined since the spring of 2006, resulting in lower energy cost savings than originally projected by the assessment. However, the methodology and results from the assessment were deemed applicable to several other Goodyear facilities and are being shared with several of those facilities.

\section{Lessons Learned}

Energy efficiency opportunities in steam systems can deliver significant energy savings without incurring substantial implementation costs. At Goodyear's tire plant in Union City, Tennessee, associates were aware of the potential for energy savings from the measures that were proposed in the Save Energy Now assessment, but were unsure that they could be implemented cost-effectively.

The assessment's calculations of implementation costs and savings revealed that the efficiency opportunities were viable enough to fit the corporate parameters for energy efficiency expenditures. As a result, plant personnel decided that they were too compelling to ignore. Because such opportunities are not plant-specific, they can be replicated in many industrial facilities that use steam.

In addition to the SSAT, other DOE software tools can be used to analyze industrial systems and processes and generate energy efficiency opportunities, including AIRMaster+, the Fan System Assessment Tool (FSAT), MotorMaster+, the Process Heating Assessment and Survey Tool (PHAST), the Pumping SystemAssessment Tool (PSAT), and 3E Plus ${ }^{\circledR}$.

\section{Save Energy Now}

Save Energy Now is a national campaign started in 2005 in response to a rapid rise in energy prices. This campaign helps U.S. industry reduce energy use and supports national goals for energy security. Through Save Energy Now, DOE's Industrial Technologies Program (ITP) helps industrial plants operate more efficiently and profitably by identifying ways to reduce energy use in key industrial process systems. Visit www.eere.energy.gov/industry/ saveenergynow for more information.

\section{A Strong Energy Portfolio for a Strong America \\ Energy efficiency and clean, renewable energy will mean a stronger economy, a cleaner environment, and greater energy independence for America. Working with a wide array of state, community, industry, and university partners, the U.S. Department of Energy's Office of Energy Efficiency and Renewable Energy invests in a diverse portfolio of energy technologies.}

For more information, contact the EERE Information Center, 1-877-EERE-INF (1-877-337-3463), www.eere.energy.gov And visit the DOE Industrial Technologies Program home page: www. eere.energy.gov/industry 